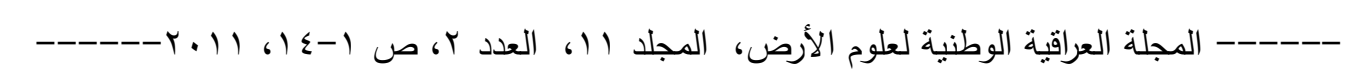

الجيولوجيا الطباقية والتركيبية لمنطقة الحمدانية حسب معطيات المسح الجيوكهربائي

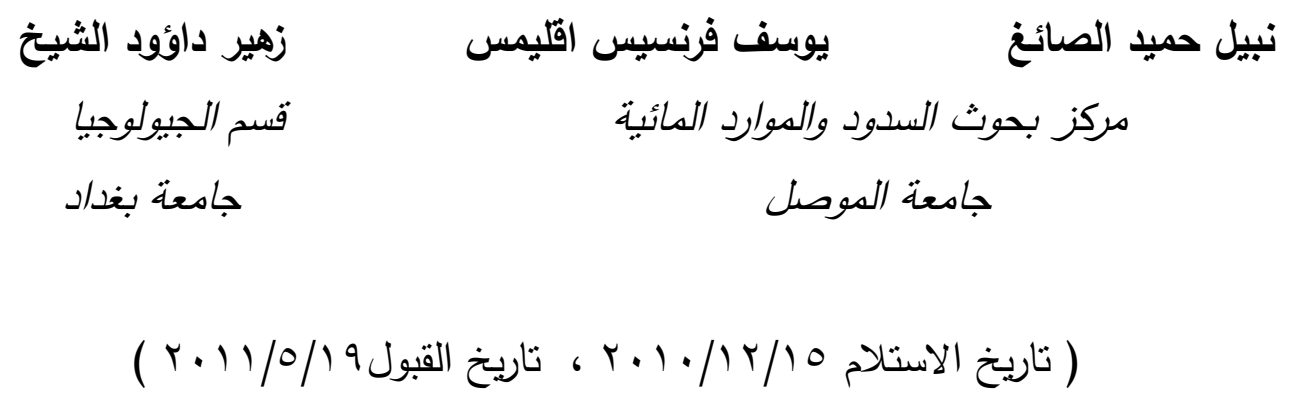

\title{
الملخص
}

تم القيام بمسح جيوكهربائي تقصيلي في قضاء الحمدانية لحوالي .90 كمّ من مساحة القضاء، وذلك من

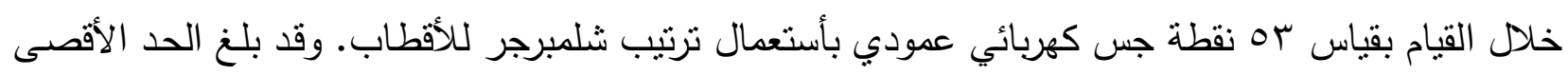

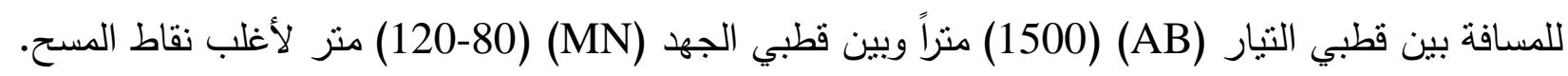
أظهر المسح الجيوكهربائي وجود أربعة أنطقة جيوكهربائية تمثل تكوينات مختلفة. النطاق الأول يمثل

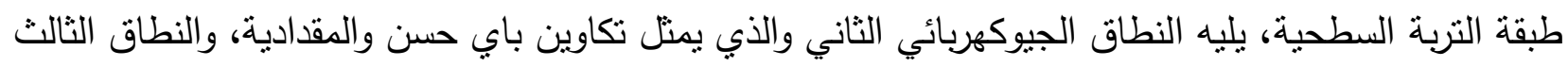

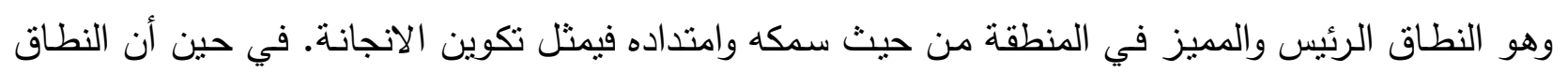

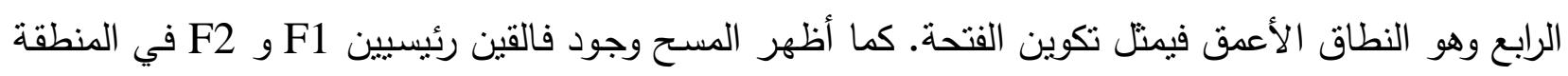
يمتدان بموازاة نهر دجلة.

\section{Stratigraphical and Structural Geology of Hamdania Area from Geoelctrical Survey}

\author{
Nabeel H. Al-Saigh Yousif F. Eclimes \\ Research Centre for Dams and Water Resources \\ Mosul University
}

\author{
Zuhair D. Al-Shaikh \\ Department of Geology \\ Baghdad University
}

\begin{abstract}
A detailed geoelectrical survey in Hamdania district for about $950 \mathrm{~km}^{2}$ from its area has been carried out, through carrying out 53 VES measurements using Schlumberger arrangement. For most measuring points the maximum distance $A B$ for the current electrodes was $1500 \mathrm{~m}$ and for the potential electrodes MN was $80-120 \mathrm{~m}$.
\end{abstract}




$$
\text { نبيل حميد الصائغ و آخرون }
$$

The survey reveals the presence of four geoelectrical zones representing different geological formations. The first zone represents the topsoil layer underlying Bi-Hasan and Mukdadyia Formations. The third geolelectrical zone represents Injana Formation, which is the main distinguished zone in the area in its thickness and extension. The fourth zone however, which is the deepest zone represents Fat'ha Formation. The survey also shows the presence of two main faults in the area F1 and F2 running parallel with Tigris River.

\section{المقدمة}

حظي قضاء الحمدانية والواقع شرق مدينة الموصل بحوالي • ككم بالعديد من الدراسات الهايدروجيولوجية

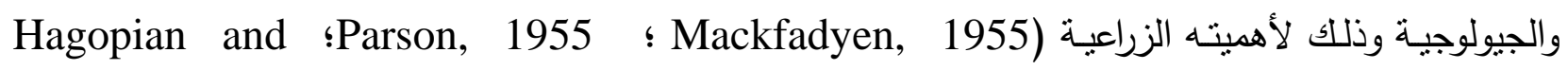
Saleh and AL-Shaikh, 1976 ؛ Vejlupek, 1977 الآبار لغرض استخدام مياهها في الثرب وري المحاصيل. ولهذا فأن مسح جيوكهربائي تفصيلي في المنطقة

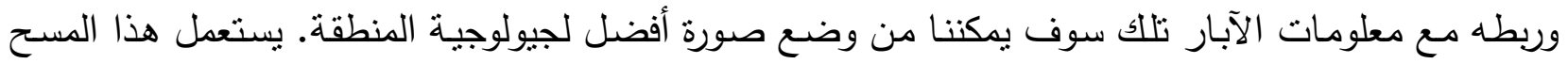

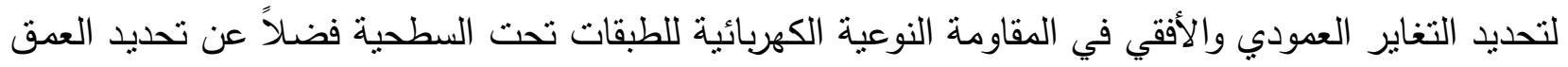
الى السطوح الفاصلة ما بين الطبقات.

\section{جيولوجية المنطقة}

تتميز المنطقة بصورة عامة بكونها قليلة التموج غير أنها تأخذ بالانحدار التدريجي من الثمال والثمال

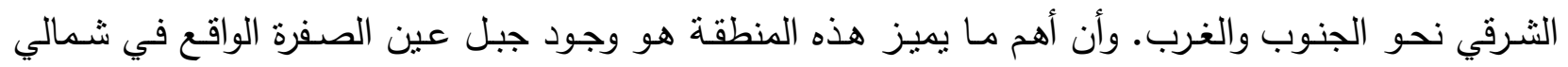

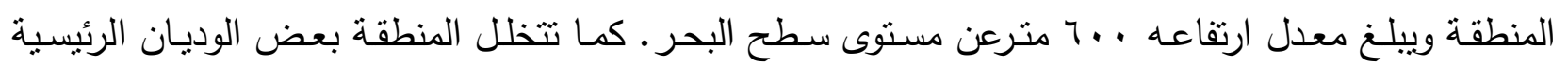
والفرعية.

تتكثف على السطح تكاوين العصر الثلاثي (Tertiary) والرباعي (Quaternary) (الثكل () وهي

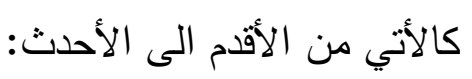




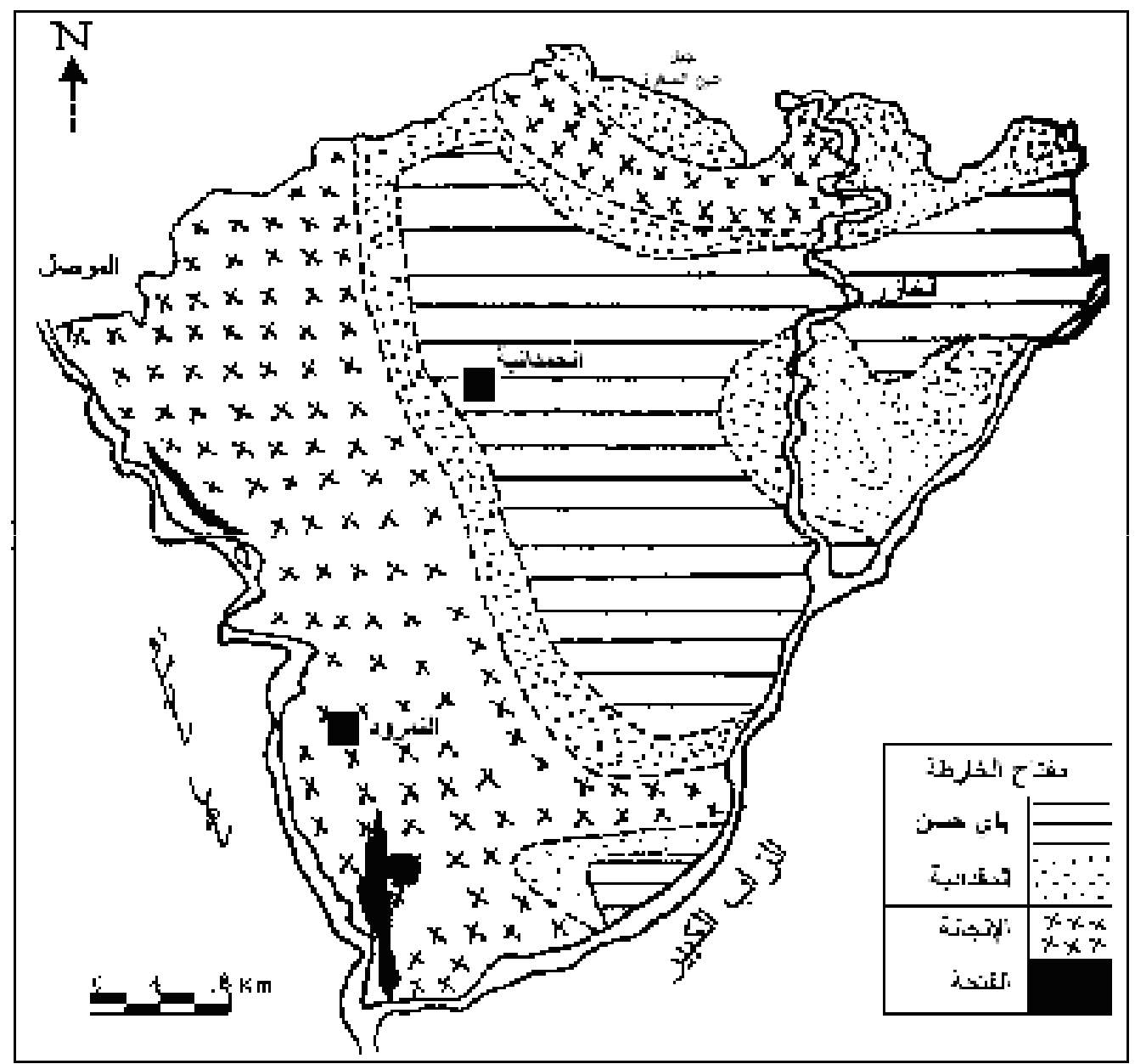

الشكل ا : الخارطة الجيولوجية لمنطقة الدراسة

أ. ترسبات العصر الثلاثي:

ا ـ تكوين الفتحة (المايوسين الأوسط)

ينكثـف هـا التكوين في أمـاكن معينـة مـن منطقـة الدراسـة وخاصـةًة في الجنـوب والجنـوب الغربـي وبالقرب من نهر دجلة. يتألف التكوين من عدة دورات نرسيبية، تمتاز كل دورة بوجود المارل الأخضر والأحمر

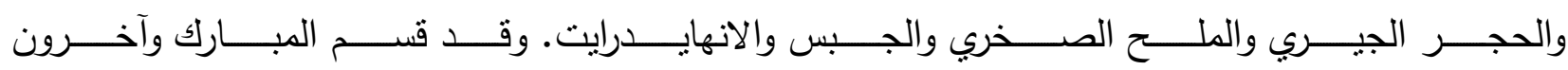
(AL-Mubarak, et al., 1977) مع حجر الجير مع وجود حجر الطين والمتبخرات، أما العضو العلوي فيتألف من حجر الطين مع حجر رملي 
ناعم فضلاً عن صخور المتبخرات. ويتم تمييز العضوين السفلي والعلوي من خـال طبقة سميكة من الحجر الجيري يتراوح سككها بين (•r-9) منراً.

r. تكوين الانجانة (المايوسين العلوي)

يتألف هذا التكوين من تعاقبات من حجر الرمل وحجر الغرين وحجر الطفل. ويشكل هذا التكوين الجزء

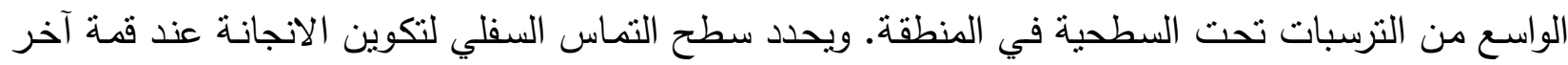

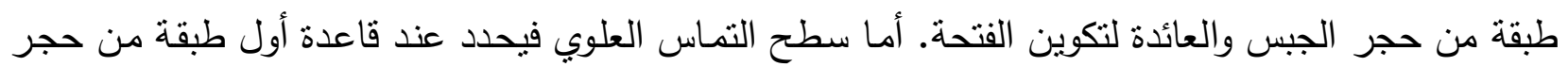
الرمل الحاوي على الحصى (Pebbles) والعائدة لتكوين المقدادية.

r. تكوين المقدادية (البلايوسين) يتألف هذا التكوين من تعاقب لحجر الرمل وحجر الطفل وحجر الغرين مع وجود أنطقة (Horizons) من حجر الرمل الحاوي على الحصى. ويتميز هذا التكوين بكسارته الناعمة ويشغل مساحات واسعة من المنطقة وخاصة في الجهة الثمالية الشرقية.

؛ ـ تكوين باي حسن (البلايوسين العلوي) يتألف هذا التكوين من تعاقب من حجر المدملكات مع حجر الرمل وحجر الغرين وحجر الطفل ويكون

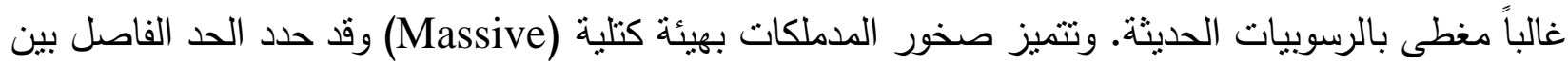
تكويني المقدادية وباي حسن من خلال سطح نوافق (Conformable) ويحدد بظهور أول طبقة من المدملكات

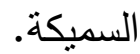

ب. ترسبات العصر الرياعي (Quaternary deposits): وتتألف من المصاطب النهرية والتربة:

ا ـ ترسبات المصاطب النهرية (River terraces) (البلستوسين) تتكون هذه الترسبات من المدملكات والحصى الحاوية على عدسات رملية وغرينية وتكون ذات امتداد واسع، وبمستويات قد تصل الى اربع مراحل وتتواجد عند ضفاف نهر دجلة والزاب الأعلى. 
r ـ ترسبات الترية (البليستوسين-الهولوسين)

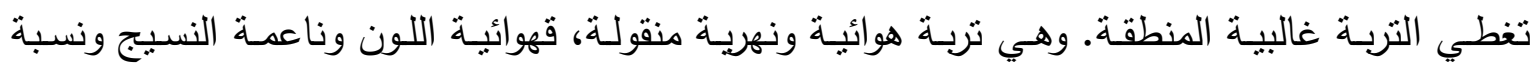
الكاربونات والكبرينات فيها عالية.

\section{العمل الحقلي وتفسير نتائج المسح}

أستخدم في المسح جهاز مسح المقاومة النوعية الكهربائية . . Terrameter SAS r ،حيث تم قياس (53) نقطة جس كهربائي عمودي (Vertical Electrical Sounding) موزعة في المنطقة (الثكل 2) وذلك فئل باستعمال ترتيب شلمبرجر وبلغت مساحة المنطقة الممسوحة حوالي (950) كمب ـ. وقد بلغ الحد الأقصى للمسافة

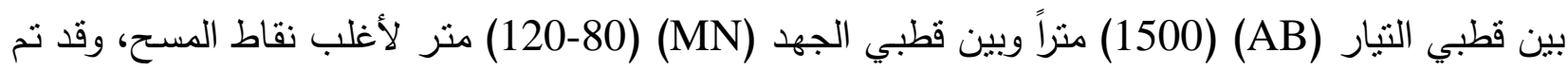

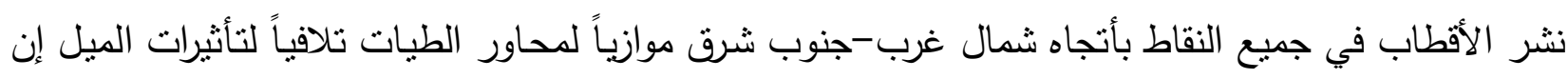
وجد.

تـم تقسـير المنحنيـات الحقليـة للمقاوميـة الكهربائيـة الظاهريـة بمضــاهاتها مـع المنحنيـات النظريـة وبمساعدة المنحنيات المساعدة (master curves) الكهربائية الحقيقية لطبقات تحت السطح وسماكاتها. وكذلك تم استخدام البرنامج المعد من قبل الثركة السويدية والذي يدعى (ABEM)

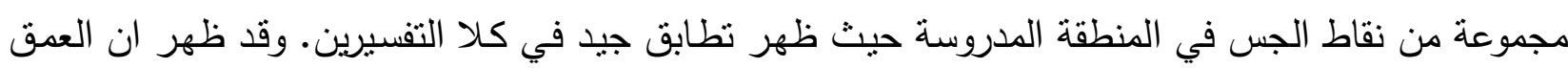
المستكثف يتراوح بين •ـ- .0\% من الفاصلة القطبية (AB/2).

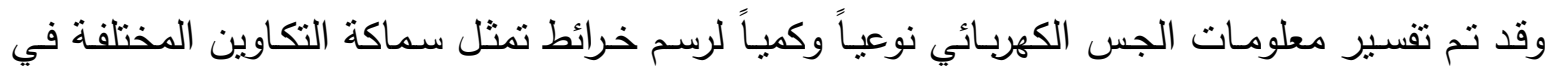




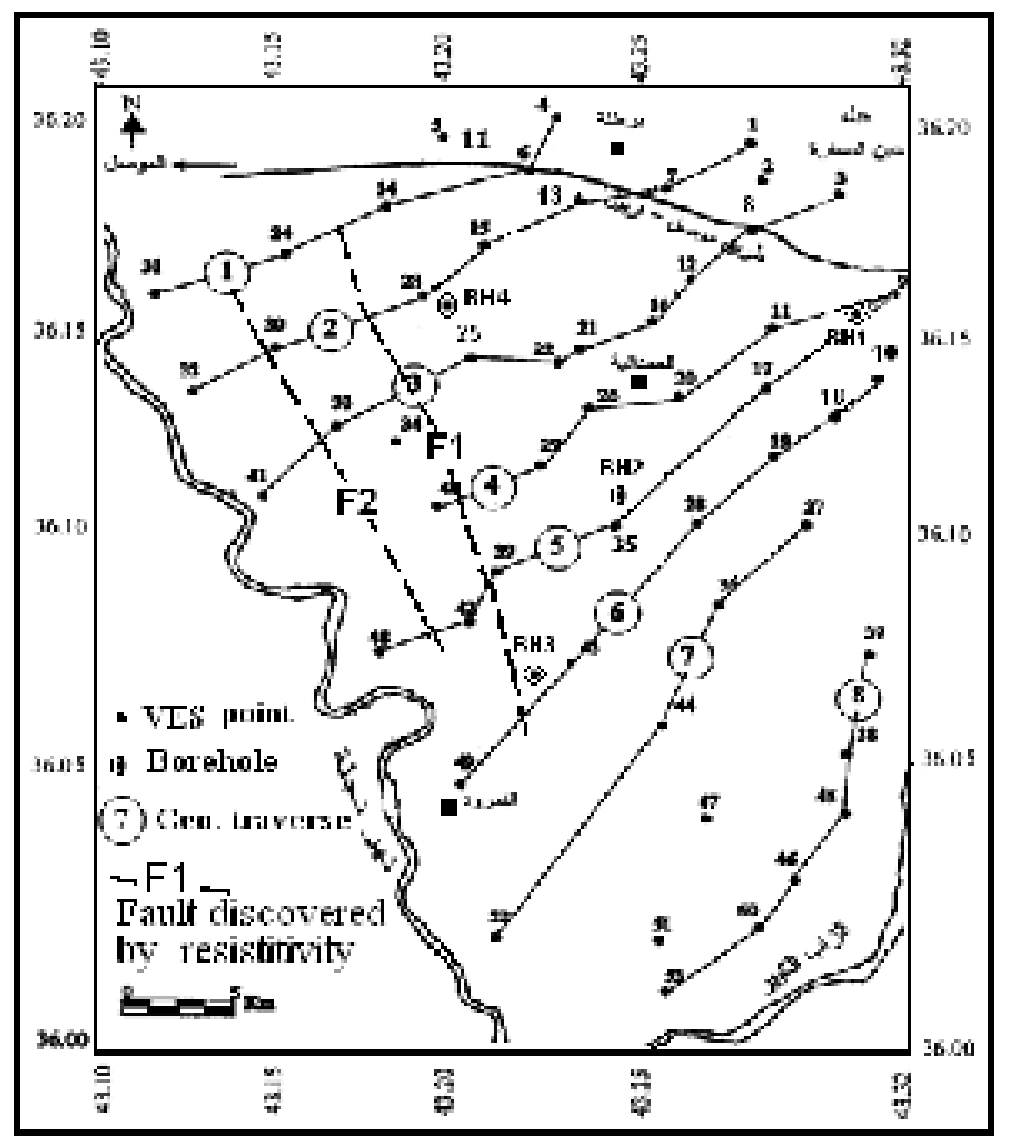

الثكل r: يظهر مسارات المسح الجيوكهربائي ونقاط الجس VES ومواقع الآبار في منطقة الدراسة.

خرائط تساوي المقاومة التوعية الكهريائية الظاهرية:

الثكل (ب) يمثل خرائط كنتوريـة لقيم تساوي المقاومـة النوعية الكهربائية الظاهريـة ولكل من المسافات

القطبية ( 600, 400, 200, 100, 40, 5=AB/2) تغطي أعماق تتراوح بين 2- . . بـم. بصورة عامة أظهرت

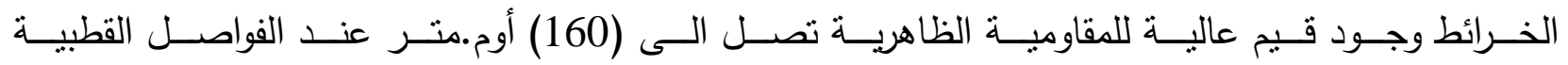
(100-5) متر في وسط منطقة الدراسة وهي على الأغلب تمنل التربة الجافة والترسبات الحديثة كما تشير الى الى ذللك آبـار كهربز (BH2) وتل عاكوب (BHY). في حين أظهرت الخرائط تجانس في قيم المقاومـة النوعيـة الظاهرية بحدود (10) أوم.متز عند الفواصل القطبية ( 100>) متر في أغلب مناطق الدراسة والتي تعكس وجود ترسبات متجانسة والتي هي على الأغلب تعود الى تكوين الانجانة المتشبع بالمياه. 
الجيولوجيا الطباقية والنركيبية لمنطقة الحمدانية حسب معطيات المسح الجيوكهربائي

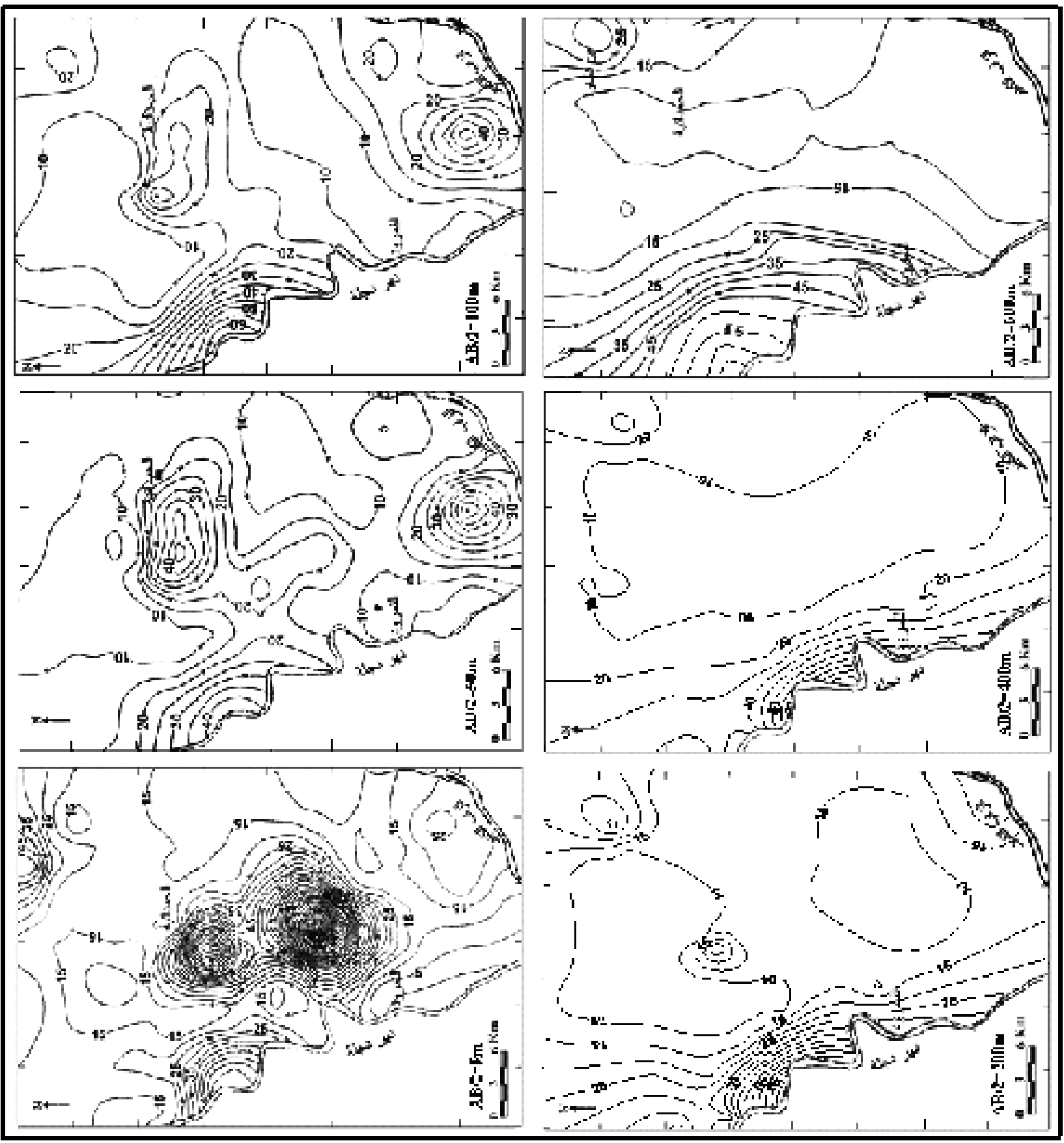

الثكل r: خرائط تساوي المقاومية لمنطقة الدراسة وللفواصل القطبية AB/2

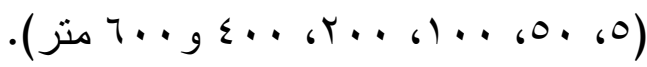


كمـا أظهرت الخرائط وجود تغير مفاجئ في قيم المقاومـة النوعية الظاهريـة في غرب منطقة الدراسـة

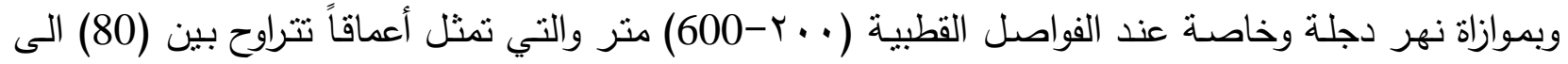

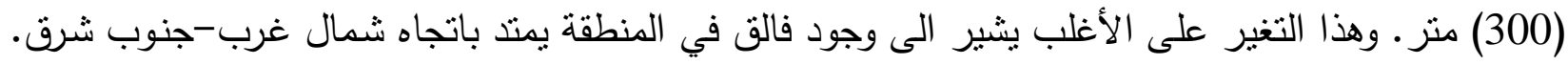

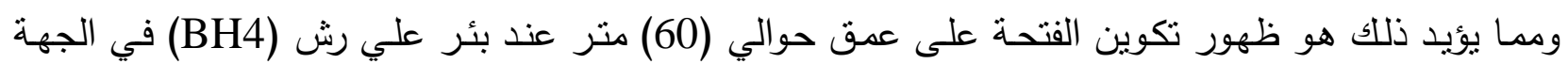

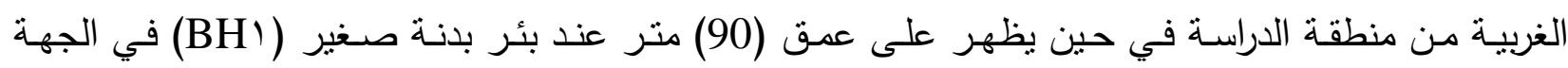

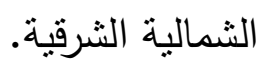

\section{(Electrical Profiles) المسارات الكهريائية} نم رسم ثمان مسارات حقلية (Profiles) تغطي المنطقة (الثكل ؟) وبأطوال تتراوح بين (17 و 33) كم. حيث تظهر في كل مسار قيم المقاومة النوعية الكهربائية الظاهرية للفواصل القطبية ( , AB/2 = 600, 400 (200, 100, 40, 5 أن المقاومة الظاهرية (م) نقل عموماً مع ازدياد المسافة القطبية (AB/2) أي أنها تقل مع زيادة العمق

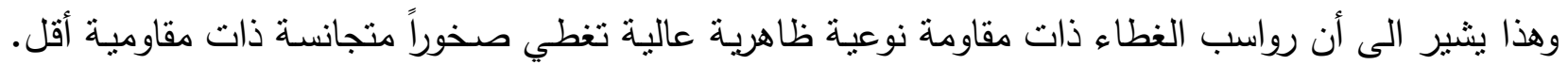

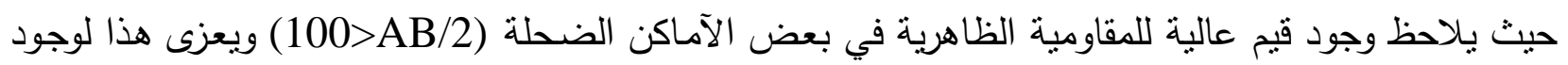

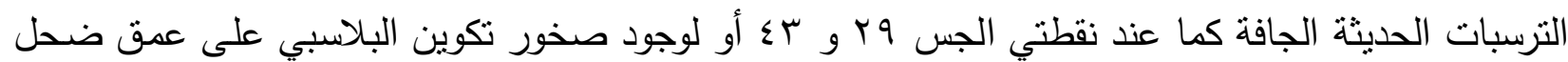

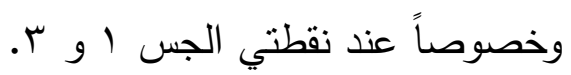
وفي الجزء الثمالي الغربي والغربي من منطقة الدراسـة وبموازاة طريق موصل-كركوك وخاصـة عند الندا الفواصل القطبية (600-200=AB/2) متر والتي تمثل أعماق تتراوح بين (300-80) متر بلاحظ قيماً عالية

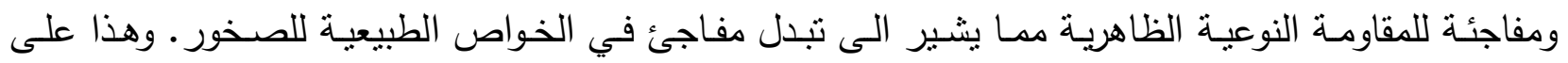

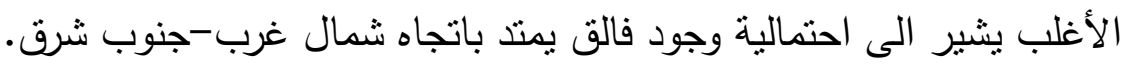

\section{المقاطع الجيوكهريائية}

رسمت المقاطع الجيوكهربائية لكل مسـار باستخدام نتيجـة التفسير الكمي لنقاط الجس الواقعة على التى المسار وربط الانطقة ذات المقاومة النوعية الحقيقية المتثابهة من نقطة لاخرى ليكون المقطع الكهربائي. وعليه فقد رسمت سبعة مقاطع جيوكهبائية على المسارات (1-7) (الشكل 0) وقد ربطت تلك المقاطع مع معلومات الآبار التي تقع على تلك المسارات او بالقرب منها. 


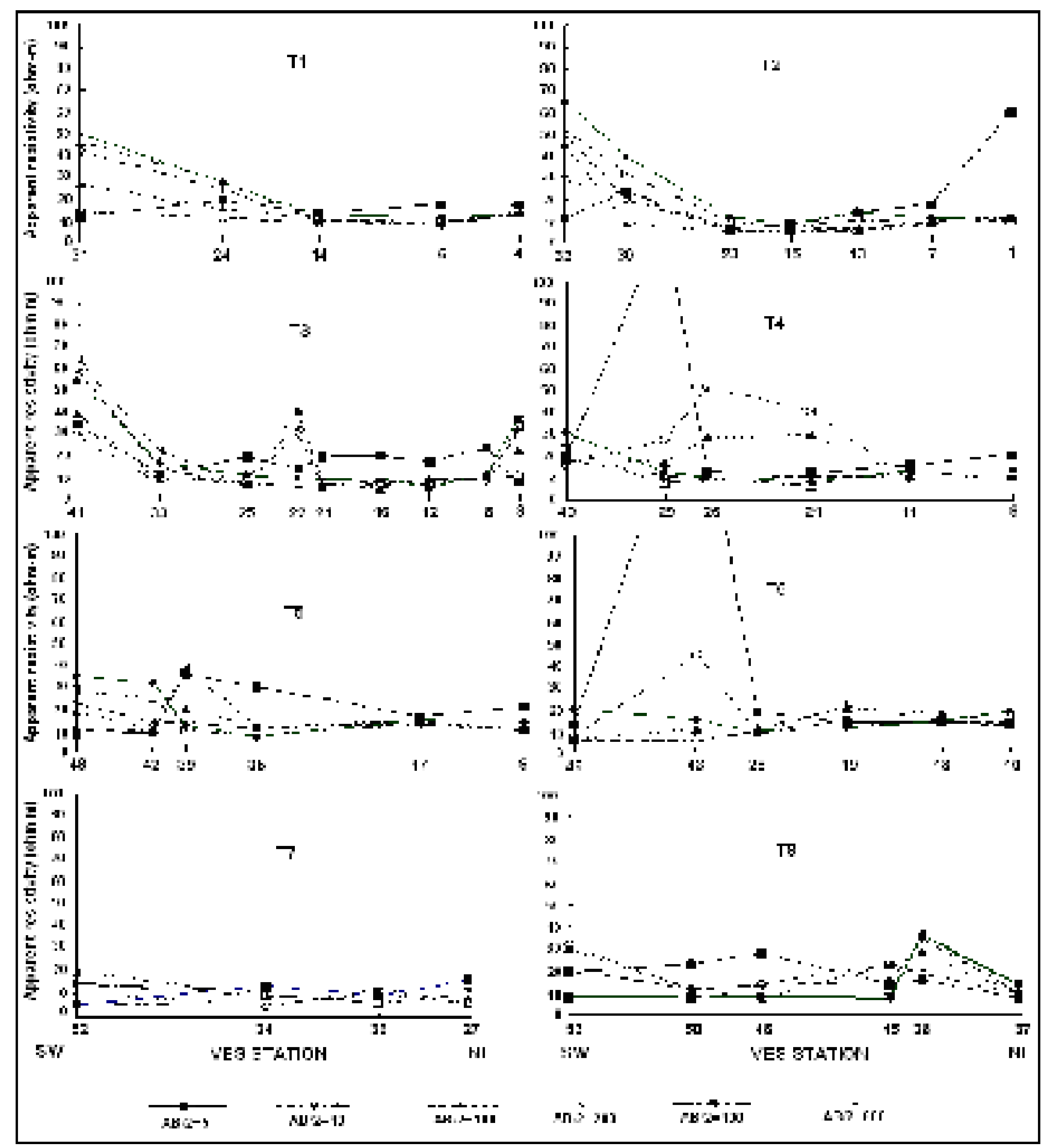

الثكل ؟: المسارات الكهربائية الحقلية

أظهرت المقاطع الجيوكهربائية عموماً اربعة انطقة جيوكهربائية حيث يتمثل كل نطاق بسمك معين وقيم متقاربة للمقاومية الحقيقية. يتميز النطاق الاول بقيم عالية للمقاومية الحقيقية تصل الى (330) اوم.متر وبسمك (لا يتجاوز rr) ، ويمثل هذا النطاق القشرة السطحية المتمثلة بالتربـة الجافةً. يليه النطاق الجيوكهربائي الثاني

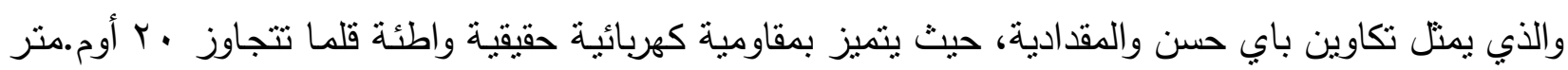
وسمك النطاق متغاير يصل الى . متراً في وسط المنطقة ولكنه بشكل عام يقل نحو الغرب والجنوب الغربي ليختفي تماماً في بعض الأماكن. 
نبيل حميد الصائغ و آخرون

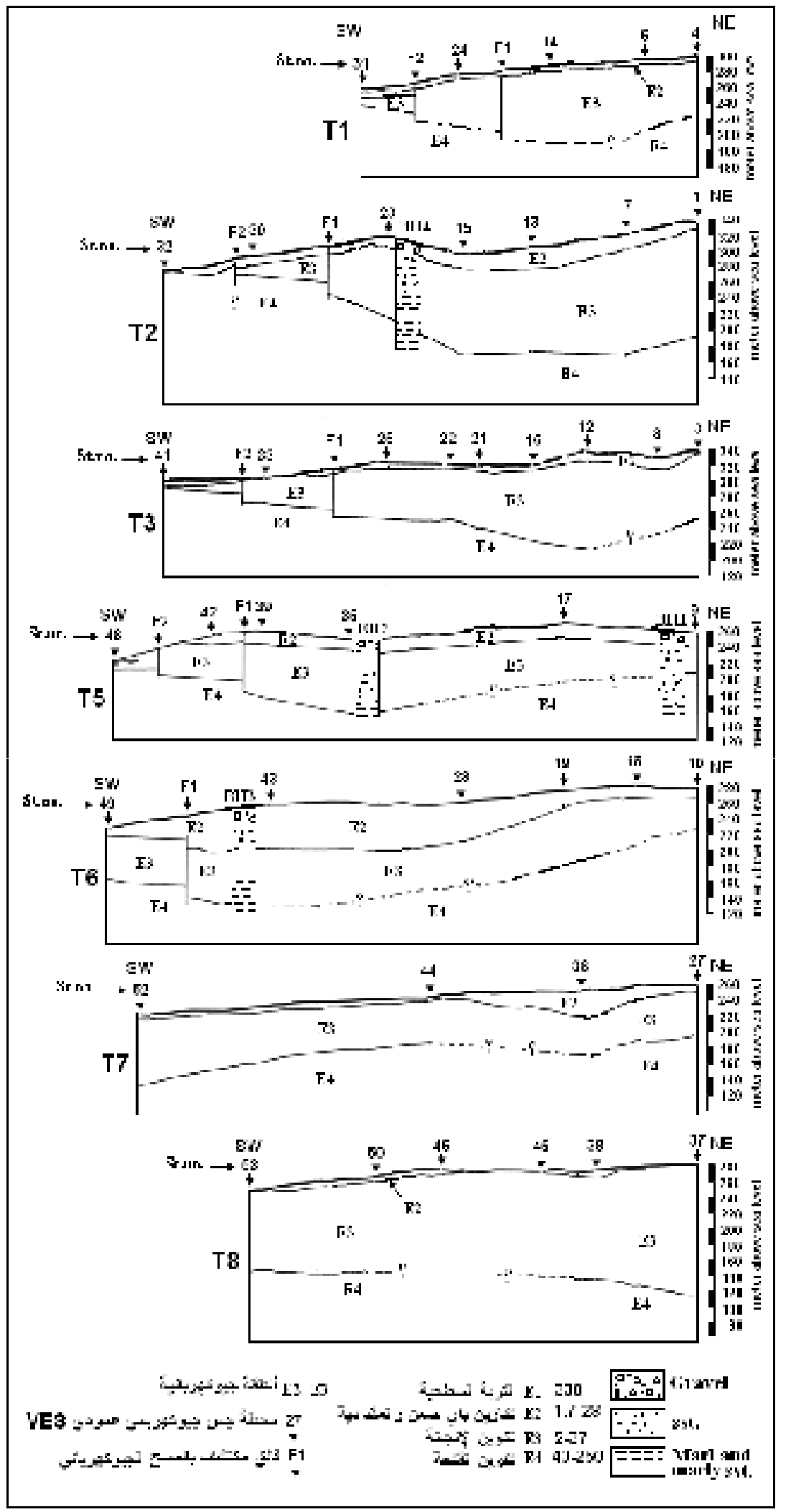

الثكل 0: المقاطع الجيوكهربائية في المنطقة 
النطاق الثالث وهو النطاق الرئيس والمميز في المنطقة من حيث سماكته وامتداداته. مقاوميته الحقيقية واطئة لا تتجـاوز (0 1) أوم.متر وسمكه يصـل في وسط منطقة الدراسـة الى ( . . ب) متر . وهو يمثنل تكوين الانجانة ومقاوميته المنخفضـة تشير الى تشبعه بالمياه. والنطاق الرابع وهو النطاق الأعمق ومقاوميته الحقيقية

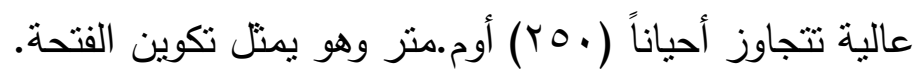
أما في الغرب والجنوب الغربي فيحصل تقلص للسمك بشكل تدرج موازي لنهر دجلة نتيجة اختفاء النطاق (E2) وتقلص سمك النطاق الثالث (E3) ليحل محلهما النطاق الرابع (E4) المتمثل بتكوين الفتحة والذي ارتفع الى الأعلى. وفي المقاطع الكهربائية أثير الى هذا التدرج بأنه نـاتج عن فالقين عموديين هـا F2, F1) حيث أدت هذه الفوالق الى رفع صخور الفتحة وكثفها في مناطق قرب النهر، لاحظ (النشكل (Step faults)

\section{خرائط تساوي العمق والسمك:}

بينت الدراسة الكهربائية الحالية التتابع الطباقي التالي، من الأقدم الى الأحدث:

خارطة عمقيه لتكوين القتحة:

لم يتوصل الجس العمودي الحالي الى قعر هذا التكوين إلا أن سطحه العلوي تم التقاطه بشكل تقصيلي وتم رسم خارطته العمقية الثكل (T) وينبين من الخارطة أن سطح الفتحة مقعراً على محور بشكل قوس يمتد جنوب شرق شمال شرق حيث يصل عمق سطح الفتحة في الجنوب الثرقي عند نهر الزاب الكبير إلى ( .9 ( ) متراً. في حين نرى عمق السطح يصل حوالي •. منراً في الجهة الغربية من منطقة الدراسة وعلى أمتداد نهر دجلة وذلك بسبب نأثير الفوالق F1 و F2 على هذا التكوين. ومن الجدير بالذكر بأن هذه الفوالق والتي شخصت خلال الدراسة الحالية تقع على امتداد فالق الموصل-حمام العليل الذي حدده الثيخ وبكر ( AL-Shaikh and Baker, 1973 وأكد استمراريته (متعب، 2000) الى هذه المنطقة.

تكوين الانجانة:

تم خلال الدراسة الحالية وضع خارطة سمكية (Isopach map) لهذا التكوين الثكل (V). حيث يظهر على العموم تشابه كبير بين الخارطة السمكية لهذا التكوين مع الخارطة العمقية لتكوين الفتحة. حيث أن سمك التكوين يقل على شكل قوس يمثد من الجنوب الشرقي (حوالي · . rم) بالقرب من نهر الزاب الى الثمال الثرقي (حوالي • ا ام) تحت جبل عين الصفرة . وتنين الخارطة أن سمك التكوين في وسط المنطقة غير منمانل فهنالك

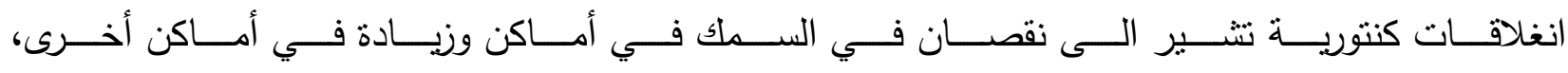




$$
\text { نبيل حميد الصائغ و آخرون }
$$

وربما يعزى ذلك الى التعرية التفاضلية خلال نرسيب فتاتيات نكوين المقدادية. كما نظهر الخارطة تتاقص في سمك تكوين الانجانة في غرب المنطقة بالقرب من نهر دجلة نتيجة الفوالقين F1 و F2 التي أدت إلى رفعه إلى السطح.

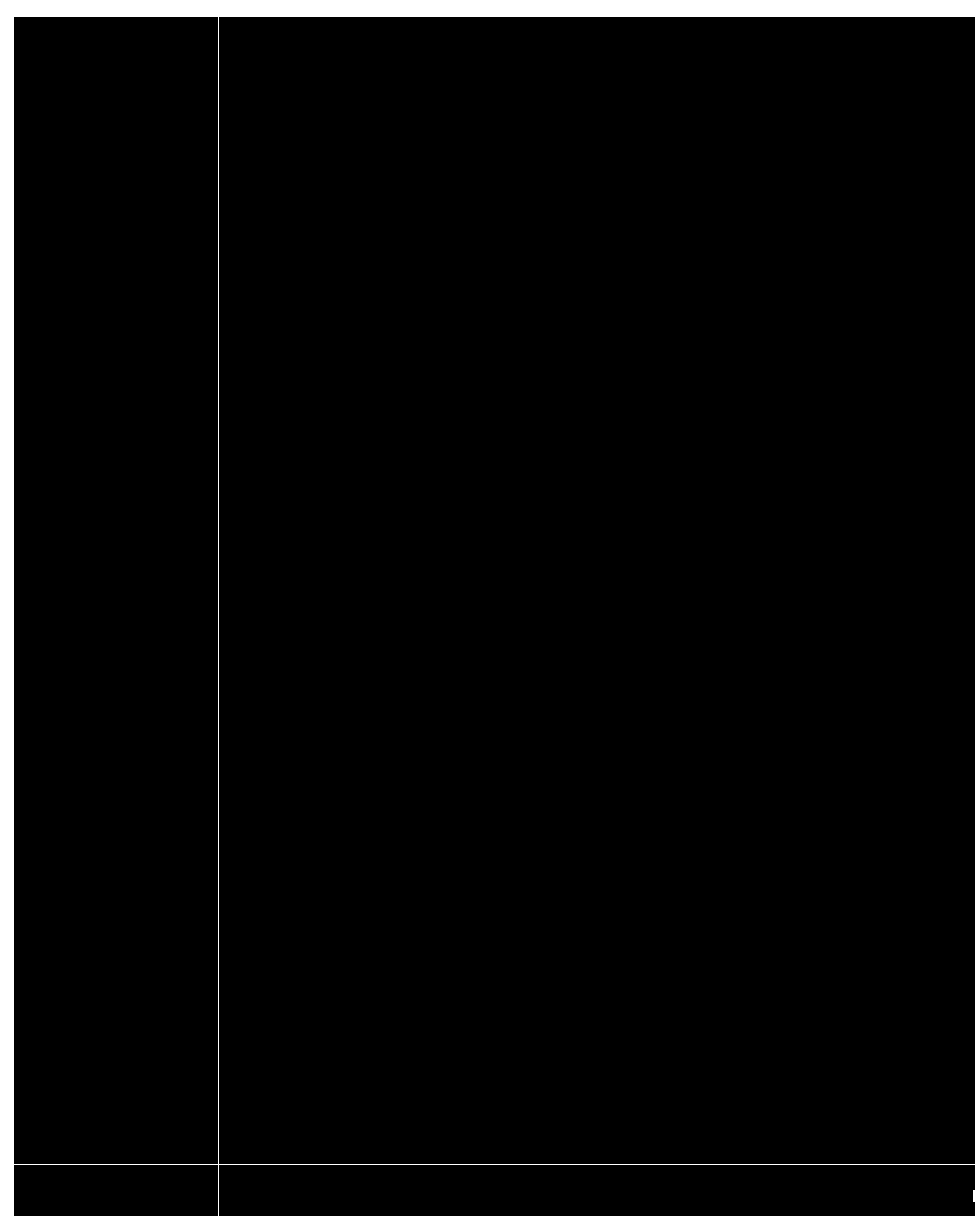


تكاوين باي حسن والمقدادية:

هذان التكوينان يشكلان النطاق الجيوكهربائي الثناني E2، ولم يكن مدكناً تميزهما عن بعضههما نظراً

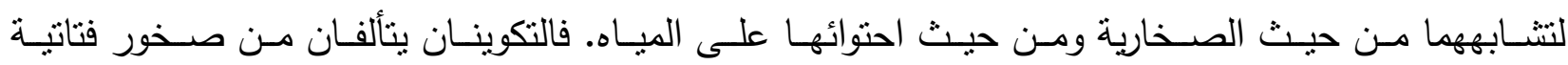

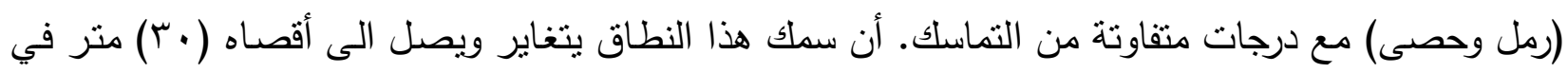

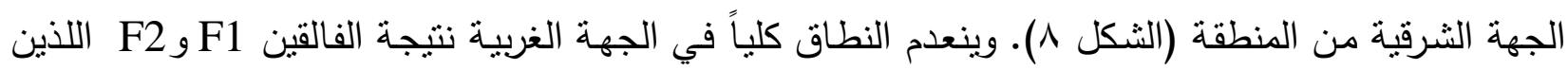
أديا الى رفعهما الى الأعلى وتعريتهما.

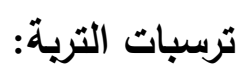
معظم أجزاء المنطقة مغطاة بتربة قهوائية اللون سلتية الى رملية ناعمة متغايرة السمك لغايـة (؟) متر

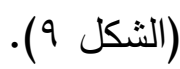

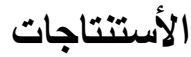

أظهرت الدراسـة الجيوكهربائية لمنطقة الحمدانيـة وجود أربعة أنطقة كهربائية. ففي الأعلى يوجد نطاق

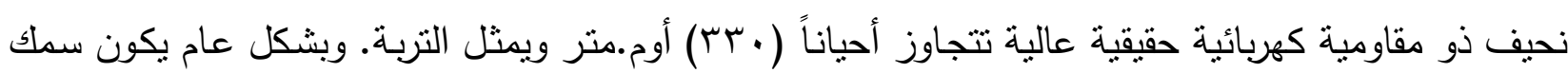

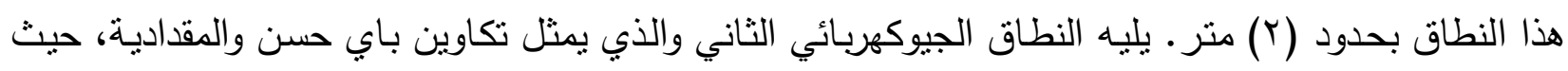

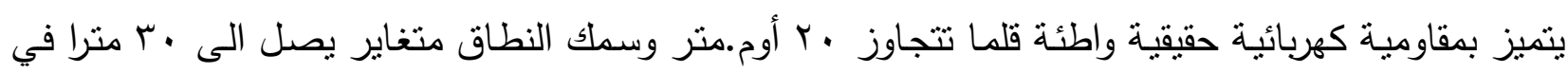

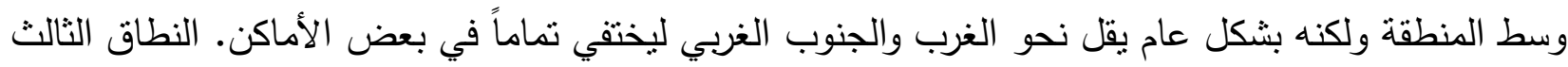
وهو النطاق الرئيس والمميز في المنطقة من حيث سماكته وامتداداته. مقاوميته الحقيقية واطئة لا تتجاوز (10)

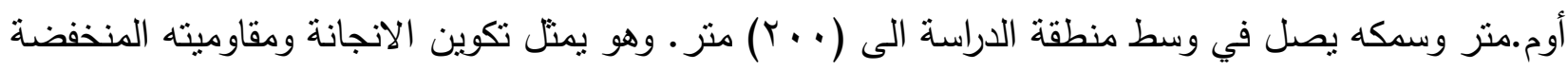

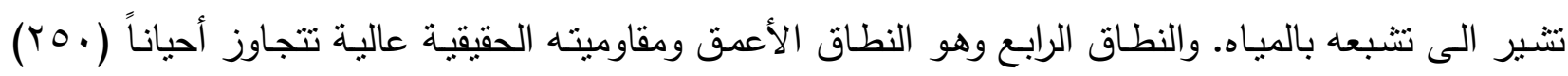

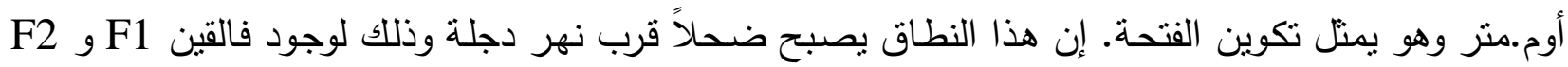
في المنطقة واللذين أديا إلى رفعه الى الأعلى وفي بعض الألى الكاكن إلى السطح. 


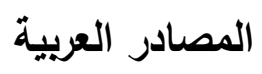

الصائغ، نبيل حميد؛ الثيخ، زهير داؤد؛ أقليمس، يوسف فرنسيس، T +. r. هيدروجيولوجية منطقة الحمدانية في

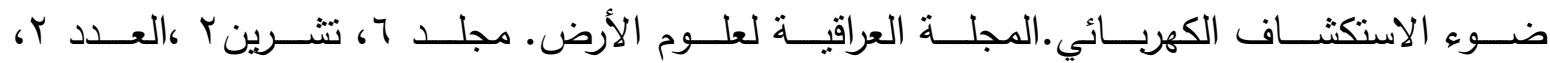
ص ص T11-OV متعب، مروان أحمد؛ الثيخ، زهير داؤد، ه . ب. إضـافات جديدة حول جيولوجيـة منطقة الموصل في ضوء

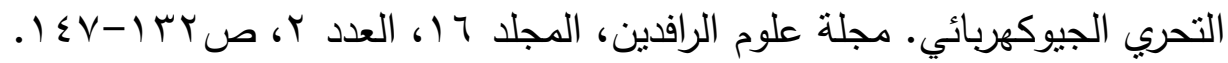

\section{المصادر الأجنبية}

Al-Shaikh, Z. D. and Baker, H. A., 1973. Gravity Survey of the Greater Mosul. Journal of the Geological Society of Iraq, Vol. `, pp. 34 - 45

Al-Mubark, M. A. R. and Yokhanna, R. Y., 1977. Report on the Regional Geology Mapping of Al-Fat'ha-Mosul. State Organization of Minerals, Library, Baghdad, Iraq.

Hagopian, D.H. and Valijuk, N., 1977. The Regional Geological Mapping of MosulErbil Area. Unpublished Report, State Organization of Minerals, Library, Baghdad, Iraq.

Mackfadyen W. A., 1955. Water Supplied in Iraq. Ministry of Development, Government of Iraq, Publication No. 1, Report No. 13.

Parson, R. M., 1955. Ground Water Resources in Iraq. Mosul Liwa, 2, State Organization of Minerals, Library, Baghdad, Iraq.

Saleh, S. A. and Al-Shaikh, Z. D., 1976. Geohydrological Condition of Mosul Area between Tigris and Greater Zab Rivers, Northern Iraq. Mining Engineering. Faculty of Engineering, Cairo University, Egypt. 